\title{
The Effect of Different Factors upon the in vitro Propagation in Quercus robur and Q. frainetto by Somatic Embryogenesis
}

\author{
Adrian I. TIMOFTE ${ }^{1}$, Doru PAMFIL ${ }^{2}$, Magdalena PALADA-NICOLAU ${ }^{3}$, Claudia S. TIMOFTE ${ }^{4}$ \\ ${ }^{1}$ University of Oradea, Faculty of Environmental Protection, 26 Gen. Magheru, 410048 Oradea, Romania; adi_timofte@yahoo.com \\ ${ }^{2}$ University of Agricultural Sciences and Veterinary Medicine, 3-5 Mănăştur, 400372 Cluj-Napoca, Romania; dpamfil@usamvcluj.ro \\ ${ }^{3}$ Forest Research and Management Institute, Research Center Simeria, 1 Biscaria, 335900 Simeria, Romania; magdalena.palada@rdslink.ro \\ ${ }^{1}$ University of Oradea, Faculty of Law and Jurisprudence, 26 Gen. Magheru, 410048 Oradea, Romania; clau_timofte@yahoo.com
}

\begin{abstract}
The somatic embryogenesis is an advanced method for clonal propagation and a useful tool for ex situ conservation of genetic resources. In this paper, the results of an experiment to investigate the influence of development stage of explants and culture medium on the germination percentage in two oak species (three provenances of Quercus robur and two provenances of $Q$. frainetto), are presented. A high significant influence of the development stage of explants and a significant influence of the interaction provenance $\mathrm{x}$ stage on the germination percentage were recorded for Q. robur explants, whilst no significant differences between the germination percentages against the nutritive media used were fould for both oak species.
\end{abstract}

Keywords: developmental stage, embryogenic induction, Quercus robur, Q. frainetto, somatic embryogenesis

\section{Introduction}

In vitro clonal propagation of oaks is an important step in the breeding activity using clonal strategies, and in the same time a tool for the application of somaclonal selection procedures in the improvement of adaptable traits.

The use of somatic embryogenesis in oak clonal micropropagation is recommended in applications concerning somaclonal variation and selection, because the plants regenerated from somatic embryos usually have monocellular origin and consist of clones of long-term culture, resulting from in vitro selection procedures. The somatic embryogenesis is an advanced method for clonal propagation and a useful tool for ex situ conservation of genetic resources.

Generally, the somatic embryogenesis can be considered an efficient mean of clonal propagation, when the following conditions are fulfilled:

-the stable embryogenic cultures constantly produce a big amount of somatic embryos;

-the embryogenic ability of such cultures can be maintained for a long time by serial adventitious embryogenesis;

-the somatic embryos can be efficiently converted into acclimatable plants.

Starting with the first successful embryogenic inductions (Chalupa, 1987a, b, 1990; Gingas and Lineberger, 1989; Jorgensen, 1988, 1993), the method was continuously improved. As a result of many experiments, nowadays is rather easy to obtain a big amount of somatic em- bryos out of juvenile explants, and also to conserve the embryogenic ability of the selected somaclones for long periods (Wilhelm et al., 1996). The embryogenesis occurs mostly direct on the explant, without a callus phase, and the stabilisation of embryogenic cultures is based on the serial adventitious embryogenesis.

The somatic embryogenesis in oak, as an alternative to vegetative propagation by cuttings, provides the possibility of mass production of cotyledonary embryos that can be either cryopreserved, or maintained by long-term culture as stable embryogenic somaclones (Wilhelm et al., 2000).

The aim of the paper is to assess the effect of the genotype, explant (developmental stage of the embryo) and culture medium upon the embryogenic induction in $Q$. robur and $Q$. frainetto.

\section{Materials and methods}

\section{Plant material}

The immature acorns of the two oak species harvested at 4 different dates were dissected and used as sources of explants. The explants were represented by immature zygotic embryos in different developmental stages or fragments of more advanced embryos. The developmental stages of zygotic embryos have been defined and correlated with the morphological characteristics of acorns (Palada-Nicolau and Hausman, 2001):

Stage 1-acorn has a diameter of 6-8 $\mathrm{mm}$ and the cup covers it almost completely: 
-the zygotic embryo of 1-1.2 $\mathrm{mm}$ is inside the acorn in an early cotyledonous stage, with the endosperm in a cenobial stage.

Stage 2 (more advanced cotyledonous but non-cumulative stage): -acorn has a diameter of about $10 \mathrm{~mm}$ and is at the level of the cup; -the zygotic embryo of $2-2.4 \mathrm{~mm}$ has a translucid but thicker cotyledons, -the endosperm, well represented, is in a cell stage.

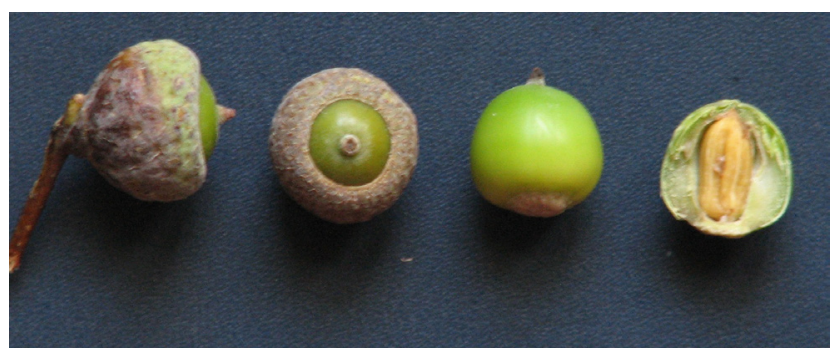

Fig. 1. Acorns in stage 2

Stage 3 is characterized by a pronounced increase and thickening of the cotyledons:

-acorn is elongated, having dimensions of $10 / 12$ $\mathrm{mm}$ and exceeds the level of the cup;

-the embryo which is also elongated (5/3-8/3 $\mathrm{mm}$ ) has thickened but still translucid cotyledons and presents only pieces of endosperm.

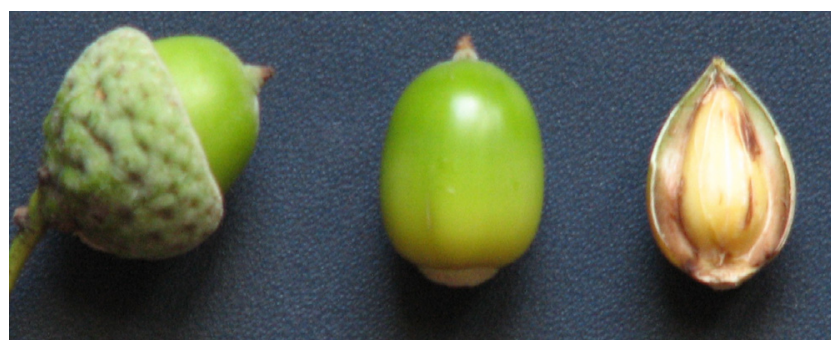

Fig. 2. Acorns in stage 3

Stage 4 is characterized by the beginning of starch accumulation in cotyledons:

-acorn is elongated, having dimensions of $10 / 14$ $\mathrm{mm}$ and exceeds the cup level;

the embryo, which is also elongated (5/3-8/3 $\mathrm{mm}$ ) has thickened, opaque cotyledons and presents only pieces of endosperm.

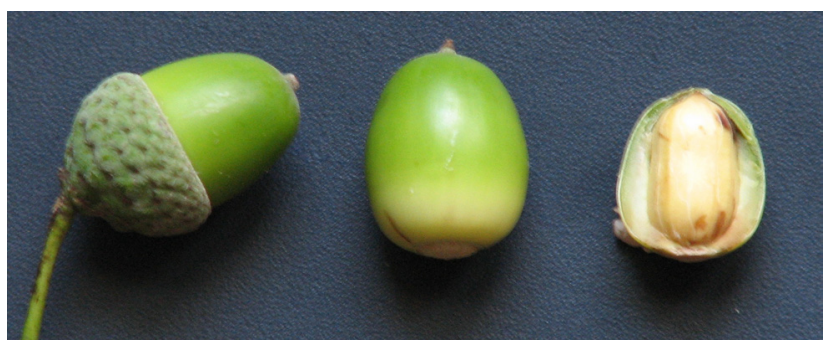

Fig. 3. Acorns in stage 4
Stage 5 defines the immature but completely formed embryos:

-acorn of $12-13 / 16-18 \mathrm{~mm}$ is only half covered by the cup

-the embryo of $10 / 7 \mathrm{~mm}$ has thick and opaque cotyledons and obvious meristematic areas (apical and radicular), and is completely without endosperm.

The young embryos, in stages 1, 2 and 3 (pre-cumulative stage) achieved in harvests 1 and 2, were wholly extracted through the dissection of the fructifications and the removal of the embryo's cover. The extraction of the embryos without being injured is very important to prevent the necrosis and the release of phenols that blacken the medium.

More advanced embryos, achieved in harvests 3 and 4 are in a cumulative stage. Only embryos in stages 4 and 5 are recommended for embryogenesis, the most advanced ones being useful only for germination in aseptic conditions.

Embryos in stages 1, 2 and 3 were integrally used while a part of the cotyledons were removed from the embryos in more advances stages.

\section{Culture medium}

Four media were tested for the induction of embryogenesis, representing combinations between two nutrient recipes 1/2 MS (Murashige and Skoog, 1962) and DCR (Durzan and Gupta, 1987) and two combinations of growth regulators:

QE1: $1 / 2 \mathrm{MS}$ with $10 \mu \mathrm{M} / 12$,4-D and $2 \mu \mathrm{M} / 1 \mathrm{BAP}$

QE2: $1 / 2 \mathrm{MS}$ with $5 \mu \mathrm{M} / 1 \mathrm{NAA}-5 \mu \mathrm{M} / \mathrm{l} \mathrm{BAP}$

QE3: DCR with $10 \mu \mathrm{M} / 12$,4-D and $2 \mu \mathrm{M} / 1$ BAP

QE4: DCR with $5 \mu \mathrm{M} / 1 \mathrm{NAA}-5 \mu \mathrm{M} / \mathrm{l} \mathrm{BAP}$

After two subcultures on this medium, a hormone-free $1 / 2$ MS medium was used for the proliferation of embryogenic structures.

The protocol

- Sterilisation of immature acorns by immersion in solution of $\mathrm{HgCl}_{2} 0.2 \%$, for 10 minutes, followed by abundant rinsing in sterile distilled water;

- Dissection of acorns in aseptic conditions, isolation of embryos and inoculation on agar solidified culture medium. Petri dishes $(\varnothing=10 \mathrm{~cm})$ containing cca. $25 \mathrm{ml} \mathrm{me-}$ dium were used. Five explants were placed in each Petri dish.

- In the case of the more developed embryos (stages 3 and 4 ) around $3 / 4$ of the cotyledons were removed, and the embryo with the basal part of cotyledons was planted on the culture medium.

- The cultures were incubated at cca. $22^{\circ} \mathrm{C}$ in darkness. The duration of subcultures ranged between 21 and 30 days.

- The observations were made at the end of first two subcultures. All reactions of the explant to the culture conditions (embryogenesis, callogenesis, rhyzogenesis and 
290

germination) were recorded. When necessary, a binocular stereomicroscope was used.

Structure of the experiment (Timofte, 2007):

- 2 oak species:

-Quercus robur,

- Quercus frainetto

- 5 provenances:

-three provenances for Q. robur (Tg. Mures, Ste-

fanesti, Dumbrava Sibiului),

Sarului). -two provenances for Q. frainetto (Griva, Padurea

- 4 developmental stages of explants (4 explant types): stages $1,2,3$ and 4

- 4 culture media, represented by :

-2 variants of nutritive medium: $1 / 2 \mathrm{MS}(\mathrm{Mu}-$ rashige and Skoog, 1962) and DCR (Durzan and Gupta, 1987),

-2 variants of growth regulator combinations, for each nutritive medium

In order to establish the effect of culture medium upon the efficiency of somatic embryo induction, comparisons were made between nutritive media (QE1 + QE2, versus $\mathrm{QE3}+\mathrm{QE4}$ ) on one hand, and between the two combinations of growth regulators $(\mathrm{QE} 1+\mathrm{QE} 3$, versus $\mathrm{QE2}+$ QE4), on the other hand.

Three replications consisting of ten explants have been counted for each parameter.

\section{Statistical analyses}

ANOVA procedure was used in order to perform analyses of variance for a three-way and a two-way layout and incomplete block design. The independent parameters were genotypes, explant stages and culture media, whilst the dependent variable was the germination percentage of the Q. robur and Q. frainetto explants used in the somatic embryogenesis experiments.

Because some experimental data had values " 0 ", the transformation $x^{\prime}=\sqrt{x}+1$ was used, all calculations being performed with transformed values (Ardelean et al., 2005).

All the results were reported to the number of viable explants.

The statistical validation of the differences among the experimental variants was made by the Duncan multiple range test and Tukey test. These tests allowed the comparison of all differences between every two variants.

\section{Results and discussion}

The main results are presented in Tab. 1 and 2, exclusively for the experimental factors (parameters) and interactions having the $\mathrm{F}$ test significant.

The results show a highly significant influence of the stage of explant and a significant influence of the interaction provenance $\mathrm{x}$ stage on the germination percentage of explants. The rest of actions and interactions appeared to be not significant.

Data from Tab. 1 also show that there were not significant differences between the three provenances (last column).

The development stage of explants had a significant influence upon the embryogenetic ability. The stage S1 led to a lower germination percentage than the stages $S 3$ and S4. The best germination results were obtained in stage S4, significantly higher than in the other stages.

In the case of $Q$. frainetto the results showed a highly significant influence of the stage of explants on the germination percentage. The rest of parameters and interactions appeared to be not significant in explants germination.

Tab. 2 presents the effect of development stage of the explant upon the embryogenic reaction of explants (germination) in Q. frainetto.

The development stage $S 4$ had a higher significant influence than the others stages on explants germination, whilst not significant difference were recorded for stages S1, S2 and S3 (S2 stage provided the lowest germination percentage).

For both oak species the results showed no significant difference between the germination percentages against the nutritive media used.

Tab. 1 The effect of provenance and developmental stage of explant upon the germination of the explants in Q. robur (Duncan test)

\begin{tabular}{|c|c|c|c|c|c|}
\hline \multirow{2}{*}{$\begin{array}{l}\text { The stage of } \\
\text { explant }\end{array}$} & \multicolumn{5}{|c|}{$\begin{array}{l}\text { The somatic embryo induction } \\
\text { and the signification* }\end{array}$} \\
\hline & S1 & S2 & S3 & S4 & $\begin{array}{l}\text { The average } \\
\text { for parameter } \\
\text { "provenance" }\end{array}$ \\
\hline Tg. Mures & $0.48 \mathrm{c}$ & $0.62 b c$ & $0.82 \mathrm{ab}$ & $0.96 \mathrm{a}$ & $0.72 \mathrm{~A}$ \\
\hline Stefanesti & $0.53 \mathrm{c}$ & $0.60 \mathrm{bc}$ & $0.64 b c$ & $0.92 \mathrm{a}$ & $0.67 \mathrm{~A}$ \\
\hline $\begin{array}{l}\text { Dumbrava } \\
\text { Sibiului }\end{array}$ & $0.44 \mathrm{c}$ & $0.54 \mathrm{c}$ & $0.55 c$ & $0.97 \mathrm{a}$ & $0.63 \mathrm{~A}$ \\
\hline $\begin{array}{l}\text { The average for } \\
\text { parameter "stage" }\end{array}$ & $0.48 \mathrm{M}$ & $0.59 \mathrm{MN}$ & $0.67 \mathrm{~N}$ & $0.95 \mathrm{P}$ & \\
\hline
\end{tabular}

*Means followed by the same letters are not significantly different. DS $5 \%$ for interaction between provenance and stage: $0.202-0.235$. DS $5 \%$ for provenance: $0.120-0.123$. DS $5 \%$ for stage: $0.120-0.130$

Tab. 2. The effect of developmental stage of the explant upon the embryogenic reaction of explants in Q. frainetto (Duncan test)

\begin{tabular}{ccc}
\hline The stage of explant & The average on stage & $\begin{array}{c}\text { The signification } \\
\text { of difference }\end{array}$ \\
\hline S1 & 0.497 & $\mathrm{~A}$ \\
S2 & 0.475 & $\mathrm{~A}$ \\
S3 & 0.570 & $\mathrm{~A}$ \\
S4 & 0.737 & $\mathrm{~B}$ \\
\hline
\end{tabular}

${ }^{*}$ Means followed by the same letters are not significantly different. DS $5 \%$ for provenance: $0.110-0.118$ 


\section{Conclusions}

The experiment showed that it is very important to harvest the acorns for somatic embryogenesis in the optimum development stage, and when this is not possible, to place a large number of explants ( 5 fold more than usually) on culture medium in order to ensure a satisfactory somatic embryo induction, due to the low efficiency of the propagation.

\section{References}

Ardelean M, Sestras R, Cordea M (2005). Horticultural experimental technique. Academicpres Ed., Cluj-Napoca, Romania.

Chalupa V (1987)a. Effect of benzylaminopurine and thidiazuron on in vitro shoot proliferation of Tilia cordata Mill., Sorbus aucuparia L. and Robinia pseudoacacia L. Biol Plant 29:425-429.

Chalupa V (1987)b. European Hardwoods, p. 224-246. In: Bonga JM, Durzan DJ (Eds.). Cell and Tissue Culture in Forestry. Vol. 3. Dordrecht, Martinus Nijhoff.

Chalupa V (1990). Plant regeneration by somatic embryogenesis from cultured immature embryos of oak (Quercus robur L.) and linden (Tilia cordata Mill.). Plant Cell Rep 9:398-401.

Durzan DJ, Gupta PK (1987). Somatic embryogenesis and polyembryogenesis in Douglas fir cell suspension cultures. Plant Sci 52:229-235.
291

Gingas VM, Lineberger RD (1989). Asexual embryogenesis and plant regeneration in Quercus. Plant Cell, Tissue and Organ Culture 17:191-203.

Jorgensen J (1988). Embryogenesis in Quercus petraea and Fagus silvatica. J Plant Physiol 132:638-640.

Jorgensen J (1993). Embryogenesis in Quercus petraea. Ann Sci For 50(1):344s-350s.

Murashige T, Skoog F (1962). A revised medium for rapid growth and bioassays with tobacco tissue cultures. Physiol Plant 15:473-497.

Palada-Nicolau M, Hausman JF (2001). Comparison between somatic and zygotic embryo development in Quercus robur L. Plant Biosystems 135(1):1-9.

Timofte AI (2007). Researches concerning the somaclonal variability in the oak somatic embryogenesis. USAMV ClujNapoca, PhD Diss. Abstr. 11-249.

Wilhelm E (2000). Somatic embryogenesis in oak (Quercus spp.). In Vitro Cell Dev Biol Plant 36:349-357.

Wilhelm E, Burg A, Berenyi M, Endelmann M, Rodler R (1996). Plantlet regeneration via somatic embryogenesis and investigations on Agrobacterium tumefaciens mediated transformation of oak (Quercus robur), p. 125-130. In: Ahuja MR, Boerjan W, Neale DB (Eds.). Somatic Cell Genetics and Molecular Genetics of Trees, Kluwer Press. 